\title{
Besi Hayvanlarında Yaralanmalar ve Önleme Yolları
}

\section{Araștırma Makalesi}

\author{
Özgül ANITAŞ ${ }^{1 *}$, Serap GÖNCÜ ${ }^{1}$
}

\section{ÖZ}

Hayvansal üretimde yaralanmalar ciddi kayıplara neden olmaktadır. Besi işletmelerinde besleme, taşıma, yükleme, tırnak bakımı, numaralama, boynuz köreltme, aşı-ilaç-tedavi aşamalarında hayvanla birebir temas olmaktadır. Bu faaliyetler hem hayvan hem de çalışan için çeşitli açılardan riskler taşımaktadır. Hayvanda muamele sırasında oluşan yaralar nedeniyle stres artmakta, verimler düşmektedir. Buna ek olarak hayvanla muamele sırasında oluşan yaralar enfeksiyon kaynağı olarak da kayıpların artmasına neden olmaktadır. Besi işletmeleri tüm bu yaralardan kaçınmak için mümkün olan en az düzeyde hayvanla temas yolunu seçmektedir. Ancak insanla teması azalan hayvanlar genel olarak daha sonraki işlemlerde daha tepkisel davranma eğilimli olacağından işler zorlaşmaktadır. $\mathrm{Bu}$ noktada besinin en önemli unsuru olan tartım işleminin yapılamaması besi takibini imkânsız kılmaktadır. Büyük ölçekli besi işletmelerinde yaşanan insan hayvan temasları ve hayvanların yönetiminde kullanılan alet ekipmanların hayvan davranış özelliklerine uygun olmaması gibi konuların göz ardı edilmesi kayıpların artmasına neden olmaktadır.

Bu çalışmada besi işletmelerinde yüz yüze anket, gözlem ve yerinde tespit yapılarak meydana gelen yaralanma düzeyleri ve önleme yolları üzerinde durulmuştur.

Anahtar kelimeler: Besi hayvanı, hayvan refahı, yaralanma.

\begin{abstract}
Injuries in animal production cause serious losses. In the breeding establishments, one-to-one contact was made with the animal at the stages of feeding, carrying, loading, hoof care, numbering, horn blunting, vaccine-drug-treatment. These activities pose risks for both the animal and the worker from various angles. Stress increases and yields decrease due to the wounds that occur during treatment in the animal. In addition, wounds that occur during treatment with animals cause increased losses as a source of infection. Fattening establishments choose the least possible contact with the animal in order to avoid all these injuries. However, things get harder as animals whose contact with humans decreases will generally tend to be more reactive in later processes. At this point, the fact that the weighing process, which was the most important element of the food, cannot be done makes it impossible to follow up the fattening. Ignoring the issues such as human-animal contacts experienced in large-scale breeding enterprises and the equipment used in animal management not being suitable for animal behavioral characteristics leads to an increase in losses. This study focuses on the injury levels and prevention methods that occur in the fattening establishments by face-to-face survey, observation and on-site detection.
\end{abstract}

Injuries in Beef Cattle and Prevention Methods

Keywords: Animal welfare, beef cattle, injury.

ORCID ID (Yazar sırasına göre)

0000-0003-4607-8594, 0000-0002-0360-2723

\author{
Yayın Kuruluna Geliş Tarihi: 27.04.2021 \\ Kabul Tarihi: 24.10.2021 \\ ${ }^{1}$ Çukurova Üniversitesi, Ziraat Fakültesi, Zootekni Bölümü,01330 Adana \\ *E-posta: ozgulanitas01@gmail.com
}




\section{Besi Hayvanlarında Yaralanmalar ve Önleme Yolları}

\section{Giriş}

İnsanların sağlıklı bir şekilde yaşaması, ekonomik ve sosyal refahını artırması yeterli ve dengeli beslenmesine bağlıdır. Günümüzde hızla artan nüfus dengeli ve yeterli beslenme konusunda verimliliği öne çıarmaktadır. Hayvansal üretimde biyolojik faktörler karlılığı çok önemli ölçüde değiştirmektedir. İnsan vücudunun yapı taşlarından olan proteini bol miktarda içeren kırmızı et önemli temel besin kaynağıdır. Kırmızı et demir, çinko ve B12 vitaminleri içeriği ile beyaz ete göre de ayrıcalık arz etmektedir. Bu nedenle kırmızı et üretiminde birim başa verimler çok önemlidir. Besi, kasaplık hayvanlarda et ve yağ miktarının artırılması, et kalitesinin yükseltilmesi yanı sıra çeşitli hayvan yemlerinin ve endüstri kalıntılarının istihdama katkısı ile ekonomiye katkıda bulunan üretim dalı olarak tanımlanabilir. Besi işletmelerinde ete ek olarak üretilen yan ürünler pek çok sektörün hammaddesi konumundadır. Besi işletmelerinde risk yönetimi açısından, yatırım sermayesinin geri dönüşü, hayvan satış fiyatları ile girdi maliyetlerine bağlı bir fonksiyon olup banka faizlerine göre yüksek getiri sağlaması sürdürülebilir üretim için ön koşuldur. Ancak besi işletmelerinde karlılık üzerine hayvanın 1rk1, yaş1, cinsiyeti, orijini, kondisyonu, bakım, besleme, sağlık koruma teknik parametreler ile işletme kuruluş yeri seçimi, işletme ölçeği, besi sistemi, optimum besi süresi, desteklemeler, finansal kayıt tutma ve pazarlama gibi birçok faktör etkilidir. Hayvan başına gelir, hayvan alış ve satış fiyatı arasındaki fark ile hayvanların beside gösterdikleri canlı ağırlık artışına bağlı farktan meydana gelmektedir. Ayrica yetiştiricinin pazar tercihi, yan ürünleri değerlendirebilme durumu, karkas sinıfi ve kalite derecesi gibi faktörler de karlılığı etkilemektedir.

TUIK verilerine göre mezbahalarda kesilen sı ğırların ortalama karkas ağırlı̆̆ı, 1991'de $150.55 \mathrm{~kg}, 1998$ 'de $175.88 \mathrm{~kg}$ (Göncü, 1993) ve son 15 yılda ise 237 kg'dan $312 \mathrm{~kg}$ 'a ulaşmıştır. $\mathrm{Bu}$ artışta işletme ölçeklerinin artışı, teknik besi uygulamas1 ile canlı hayvan ithalatının etkili olması muhtemeldir. Ancak, aynı 1rkla çalışan besi işletmelerinde 700 gram ile 1800 gram arasında değişen günlük canlı ağırlık artışı elde edilmesi, çevre bakım besleme ve yönetimin farklılıklarını göstermektedir. Besicilik kesikli üretim yapılabilen, bir iş kolu olduğu için stres konusu göz ardı edilebilmektedir. Oysa besideki hayvanlar, çok yer değiştirdiği ve daha karışık ve değişken sürülerden geldikleri, farklı orijinli hayvanların bir arada yaşaması ile yapılan üretim dalı olması ile stres bu sürülerde de etkisini verim düşüklüğü olarak göstermektedir. İthal edilen kültür 1rk1 ve melezlerinde beklenen performansın yakalanamaması yönetsel ve bakım konusunda problemler olduğunun göstergesi olarak kabul edilmelidir. Besi sonu canlı ağırlık değerinin kalıtım derecesi yüksek olup (Brown ve Gacula, 1964) beklenen ile gözlenen canlı ağırlık arasındaki fark genel olarak bakım besleme ve yönetim hatalarının sonucu olarak kabul edilir. Ayrıca büyük ölçekli besi işletmelerinde yaşanan insan hayvan teması ile hayvan yönetiminde kullanılan alet ekipmanların hayvan davranış özelliklerine uygun olmaması gibi konuların göz ardı edilmesi kayıpların artmasına neden olmaktadır (Göncü, 2019).

Sı ğırın yaşadı ̆̆ önemlidir. Korku çok güçlü bir stres kaynağ 1 olup hayvanla çalışma sırasındaki yanlış yaklaşım ve uygulamalar farklı seviyelerde psikolojik strese neden olur. Stermer ve Camp (1981), kötü tasarlanmış tesislerde kaba davranışların, iyi tasarlanmış tesislerde iyi davranılanlara göre daha yüksek kalp atış hızına neden olduğunu bildirmektedir. Brown ve Gacula (1964), tarafindan 7 besi işletmesinde yürütülen bir araştırmada, 7 besi işletmesinin 5 'inde hayvanların \% 1.6 ile \% 7.8 yaralanma olduğu bildirmektedirler. Yaralanmalar sığırlarda herhangi bir şekilde zorlama, vurma, çarpma gibi bir güç uygulaması sonrasında gelişir ve olumsuz hayvan refahı göstergesi olarak kabul edilir. Ancak sadece canlı hayvanda değil kesim sonrası süreçlerde de çürükler, karkas derisi çıkarıldıktan sonra görünür hale gelen deri altı lezyonlardır. Karkas kalitesi (et kalitesi) açısından bu yara bereler önemli olup kalite sinifların belirlenmesinde etkilidir. Hayvandaki küçük ya da büyük çaptaki yaralanmalar kesim zamanına kadar iyileşmiş olsa bile yaptığ 1 stres ve acı nedeniyle kilo 


\section{Besi Hayvanlarında Yaralanmalar ve Önleme Yolları}

kaybına neden olması ihtimali de vardır. Ayrıca hayvanın yaşadığı kötü tecrübeler daha sonraki ișlem ve uygulamalarda daha yüksek düzeyde tepkiye neden olmasiyla da üretimi etkilemektedir. $\mathrm{Bu}$ nedenle besi işletmelerde hayvanların ilk geldiği günden satışa kadar geçen sürede yaşadığ 1 tecrübeler işletmenin iş düzenini, çalışan güvenliğini ve verim düzeyini etkilemektedir.

$\mathrm{Bu}$ noktadan hareketle, bu çalıșmada besi işletmelerinde yüz yüze anket, gözlem metotları kullanılarak risk unsurları, yaralanma düzeyleri ve muhtemel yaralanmaları önleme yollarının araştırılması amaçlanmıştır.

\section{Materyal metod}

Araştırmanın materyalini, sığır besiciliği yapan işletmelerden anket ve gözlem yoluyla elde edilen birincil veriler oluşturmaktadır. Anketler; karşı1lılı görüşmeler ve gözlem sonucu doldurulmuştur. Çalışma Doğu Akdeniz bölgesi olarak tanımlanan Mersin, Osmaniye, Hatay,

Maraş ve Adana ili (Şekil 1) sınırlarında yer alan kapasiteleri 200 ile 10.000 baş arasında değişen 108 besi işletmesinde 16000 tosuna ait değerlendirme yapılmıştır. Anketler ise ziyaret sırasında işletmede çalışmakta olan kişilerle yapılmış olup toplam 223 anket uygulanmıştır.

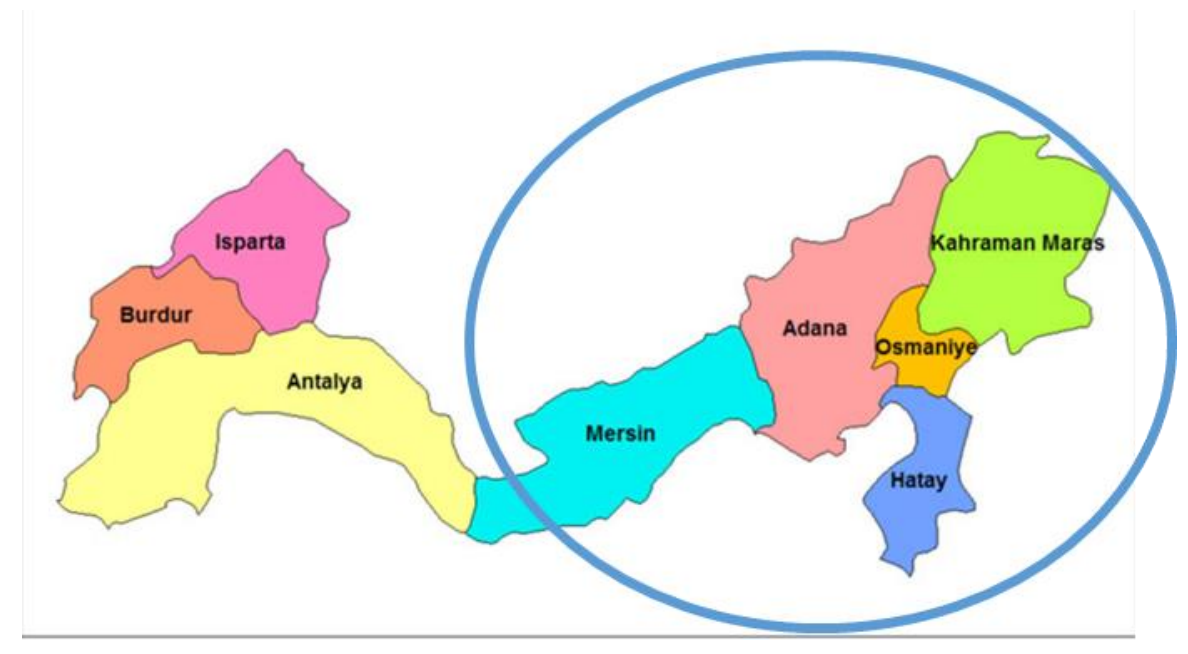

Şekil 1. Anket ve gözlemlerin yürütüldüğü iller

Çalışma bölgesi iklim tipi Akdeniz iklimi olup yazlar sicak ve kurak, kışlar yağıșlı ve 1lıktır. En sicak aylarda sicaklık ortalama 28-30 derece arası olurken, en soğuk aylarda ortalama 8-10 derece arasındadır. Yıllık ortalama sicaklık 18 derecedir. Don olayları ve kar yağışlarına çok ender şekilde rastlanır. Yağış en fazla kıș aylarında düşerken, en az yağıș yaz mevsiminde düşmektedir. Yıllık yağış miktarı 600-1000 mm arasında değişim gösterebilmektedir. Çalışma alanı illerine ait 2019 yılı sığır varlığı Çizelge 1 'de verilmiştir.

Çizelge 1. Çalışma alanı illeri 2019 yılı sığır varlığı (Tarım ve Köyişleri Bakanlığı (TKB), 2020)

\begin{tabular}{|l|l|l|l|l|l|}
\hline Irklar & Mersin & Adana & Maraş & Osmaniye & Hatay \\
\hline Kültür & 68.504 & 124.426 & 105.830 & 46.234 & 92.259 \\
\hline Melez & 58.265 & 110.459 & 109.294 & 32.044 & 46.134 \\
\hline Yerli & 3.732 & 24.374 & 4.672 & 1.553 & 7.596 \\
\hline Toplam & 130.501 & 259.259 & 219.796 & 79.831 & 145.989 \\
\hline Nüfus (milyon) & 1.648 & 2.237 & 1.154 & 538.759 & 1.618 \\
\hline
\end{tabular}




\section{Besi Hayvanlarında Yaralanmalar ve Önleme Yolları}

$\mathrm{Bu}$ çalıșma kapsamında yapılacak anket ve gözlem çalışması için işletmelere aşı, ilaç, tartım gibi uygulamaların yapıldığı günlerde gidilmiş uygulama sırasında gözlem ve tespit çalışması yürütülmüştür. Hayvanlarda

- Yara, bere, kırık, çıkık gibi fiziksel durumlar1

- Kaçmaya çalışma, sesliliğin artması, tekmeleme, vurma, çarpma, kayma veya mücadele davranışları

- Hayvanın çalışanlar ve uygulamaya tepkileri için hayvan tercih ve kaçınma davranışları

- Hayvan bakım yerine giriş süresi, girişe kadar hayvana müdahale sayısı, hayvanın geriye dönüşleri

- Elektrik şoku veya sopa kullanımı

- Tosunlara işlem yapılırken elektrikle hareket ettirilen sığır sayısı,

- S1kıştırma koridorundan çıkarken düşen, tökezleyen sığır sayısı

- Birbiri üzerine atlama sayıları alınmıştır (Grandin, 1997)

Hayvan refahı bakımından sağlıklı değerlendirme yapabilmek için işletmelerde bulunan sığırlardan en az \%10'un değerlendirilmesi istenilmektedir. Bu nedenle çalışma ve ahır koşullarının etkisini gösterebilmek adına her işletmede uygulama sirasında uygulama yerine alınan bir bölmeden en az 100 baş sığırın değerlendirilmesi amaçlanmıştır. İşletmede bir bölmede 100 baş sığır olmadığı durumlarda işletmedeki diğer bölmelerde bulunan sığırlar da değerlendirilmiştir. Sığır ırkları karışık olup

\section{Araştırma bulguları ve tartışma Demografik yapı}

Çalışmaya dahil edilen besi işletmelerinde çalışan sayısı, eğitim durumu, yaş, deneyim genel olarak, Güney Anadolu Kırmızısı, Angus, Hereford, Brangus, Şarole, Limuzin, Belçika mavisi gibi farklı irklardan oluşmuştur.

Anket soruları ve işletme çalışanları demografik bilgileri ile uygulamaya dair bilgileri içerecek şekilde hazırlanmıştır. Anket formunda 12'si demografik, 28'i durum tespit olmak üzere toplam 40 soru yer almıştır. Hazırlanan sorular, önce 3 ayrı işletmede uygulanarak soruların anlaşılırlığı tespit edilmiş ve gerekli düzeltmeler yapıldıktan sonra saha uygulamasına geçilmiştir. Anket uygulaması yüz yüze görüşme şeklinde gerçekleştirilmiştir. Hazırlanan sorular, önce yakın 3 işletmede uygulanarak anketin anlaşılırlığ 1 tespit edilmiş ve gerekli düzeltmeler yapıldıktan sonra saha uygulamasına geçilmiştir. Anket sonuçlarının değerlendirilmesinde araştırma amaçlarına göre

çapraz tablolar SPSS for Windows 6.01 istatistik programı ve MS Excel programı kullanılarak oluşturulmuştur. Daha sonra anket sorularına verilen cevaplar ve gözlem sonucu tespit edilen yara bere gözlem sonuçları kullanılarak sayı ve frekanslar excel programı formül fonksiyonu kullanılarak yapılmıştır. İşletmelerde tespit edilen yara bereli hayvan sayısının toplamının topam gözlem yapılan işletme sayısına bölünmesi ile yüzde değeri hesaplanmıştır. Burada aynı hayvanda birden çok düşme, kayma, geri dönüş atlama, elektrik şoku kullanımı her işletmede ayrı gözlem olarak değerlendirmeye alınmıştır.

$\mathrm{Bu}$ çalışma, SPSS for Windows 6.01 istatistik programı ve MS Excel programı kullanılarak hazırlanmıştır.

durumlarına ait ortalama ve yüzde dağılımları Çizelge 2.'de verilmiştir. 


\section{Besi Hayvanlarında Yaralanmalar ve Önleme Yolları}

Çizelge 2. İşletmeci ve çalışanların eğitim, yaş, deneyim durumları ve birey sayısı

\begin{tabular}{|c|c|c|c|c|c|c|c|c|c|c|c|}
\hline \multirow[t]{2}{*}{ Çalışan } & \multicolumn{2}{|c|}{ Eğitim düzeyi } & \multicolumn{3}{|l|}{ Yaş } & \multicolumn{3}{|c|}{ Deneyim } & \multicolumn{3}{|l|}{ Sayıs1 } \\
\hline & Say1 & $\%$ & Grup & Say1 & $\%$ & Grup & Say1 & $\%$ & Grup & Say1 & $\%$ \\
\hline $\begin{array}{l}\text { O.yazar } \\
\text { değil }\end{array}$ & 19 & 8.52 & $18-25$ & 38 & 17.04 & $1-4$ & 33 & 14.80 & $2-3$ & 64 & 28.70 \\
\hline Okuryazar & 29 & 13.00 & 26- 31 & 37 & 16.59 & $5-10$ & 51 & 22.87 & $4-6$ & 47 & 21.08 \\
\hline İlkokul & 103 & 46.19 & $32-37$ & 57 & 25.56 & $11-15$ & 43 & 19.28 & $6-9$ & 56 & 25.11 \\
\hline Ortaokul & 28 & 12.56 & $38-43$ & 35 & 15.70 & $16-20$ & 41 & 18.39 & $10-12$ & 41 & 18.39 \\
\hline Lise & 32 & 14.35 & $44-49$ & 40 & 17.94 & $21-25$ & 32 & 14.35 & $13-15$ & 9 & 4.04 \\
\hline Üniversite & 12 & 5.38 & $50-55$ & 16 & 7.17 & $25+$ & 23 & 10.31 & $15+$ & 6 & 2.69 \\
\hline
\end{tabular}

İşletmeci ve çalışanların eğitim durumları özellikle ortaokul ve öncesi düzeyinde yoğunlşatığı (\% 67.71) olduğu görülmektedir. Okuryazar olmayan çalışan oranı ise $\% 8.52$, lise mezunlarının oranı $\% 14.35$ ve üniversite mezunlarının oranı ise \% 5.38 olarak bulunmuştur. Genel olarak hayvancilık işletmelerinde çalışanların eğitim durumu Tugay ve Bakır (2004), ilkokul (\% 54), tahsili olmayan $\% 19.3$ olarak Soyak ve ark. (2007) ise ilkokul (\% 59) olarak bildirmektedir. Ayrıca bu çalışma sırasında işletme ziyaretlerinde işletmelerin \% 60'ında yabancı uyruklu işçilerin de zaman zaman geçici olarak görev alabildikleri tespit edilmiștir. Besi ișletmelerinde çalışanların yaș ortalamas1 15-49 aras1 (Y1ldırım, 2000), 48.4 (Şahin ve ark., 2001) ve 46.83 (Koyubenbe, 2005) olarak bildirilmektedir. Bu işteki deneyimlerinin \%56'sinın 1-10 yıl arasında yoğunlaştığ 1 tespit edilmiştir.

Besi sonunu belirlemede işletmelerin çoğunluğu (\%71.9) hayvanların kesim yaşı ağırlığını esas aldığı, \%21'i pazarda yeterli fiyat oluşumunu beklediğini ifade etmişledir. İşletmelerin \% 73.1 'inde hayvanların tartılmadığ 1 , ancak \% 14 işletmeci satmadan önce tartım yaptıklarını bildirirken, sadece \%5.3'ü aylık ve satmadan önce tartım yaptıklarnı bildirmişlerdir.

Günlük canlı ağırlık artış kontrolü yapan işletmelerin \%65.4'ü günlük ağırlık artışını 500$700 \mathrm{~g}$ olarak bildirirken, bunu \% 22.4 oraniyla $800-1000 \mathrm{~g} \% 12.2$ si ise $1200-1800 \mathrm{~g}$ olarak bildirmektedir. Benzer araştırmalarda günlük canlı ağırlık artışını Eren (2006), 1230 gr ve Köknaroğlu ve ark. (2006), çeşitli gruplarda sirasiyla $1130 \mathrm{~g}, 1180 \mathrm{~g}$ ve $1320 \mathrm{~g}$ olarak bildirmişlerdir. İşletmecilerin $\% \quad 60.1^{\prime} \mathrm{i}$ hayvanların besi sonu canlı ağırlığını $500-700 \mathrm{~kg}$ olarak tahmin etmektedir. İşletmelerde randıman genel olarak \% 45-50 arasında beyan edilirken, az oranlarda da olsa \% 50-65 arasinda bildirilmesi, işletmelerin yerli 1 rkın yanında melez ve kültür irkları yetiştirmelerinden kaynaklanmaktadır. İşletme sahipleri ve çalışanların hayvan idaresi konusunda herhangi bir eğitim alıp almadıkları sorulduğunda ise eğitim almadıkları ama genel olarak hayvancılık bilgilerini işletmedeki tecrübeli çalışan ve internet üzerinden edinmeye çalıştıklarını ifade etmişlerdir.

\section{Yaralanmalar}

Hayvanla çalışırken hayvanlara vurmak, dürtmek, yere düşen hayvanları sürüklemek, kasıtlı olarak kapıları hayvanlara çarpmak veya kasitlı olarak yere düşen hayvanların üzerine diğer hayvanları sürmek kötü sürü yönetim uygulamaları olup hayvan üzerinde stres oluşturur. Strese ek olarak fiziksel olarak da hasar bırakır. Bu çalışmada yapılan ziyaretler sırasında işletmelere neden aylık tartım yapmadıkları sorulduğunda çok zor bir işlem olduğu, hem hayvan hem de çalışan açısından zor ve stresli bir iş olduğunu ve stres yapmamak adına tartımı mümkün mertebe az yapmayı tercih ettiklerini bildirmişlerdir. Bu çalışmada 


\section{Besi Hayvanlarında Yaralanmalar ve Önleme Yolları}

kapasiteleri 50 ile 10.000 baș arasında değișen 108 besi işletmesinde toplam 1200 tosunun değerlendirmesi yapılmıştır. Yapılan gözlem ve tespit sonuçlarına ait ortalama değer ve yüzde oranları Çizelge 3'te verilmiştir.

Çizelge 3. Çalışmada uygulama sırasında yapılan gözlem sonuçları

\begin{tabular}{|l|l|l|}
\hline Kriter & Sayı & Yüzde \\
\hline Hayvanın çalışanlar ve uygulamadan kaçınma davranışı (Adet) & 1769 & 16.38 \\
\hline Koridordan çıkarken tökezleme (Adet) & 1251 & 11.58 \\
\hline Elektrik şoku veya sopa kullanımı (Adet) & 1247 & 11.55 \\
\hline Koridordan çıkarken düşenler (Adet) & 1116 & 10.33 \\
\hline Hayvan bakım yerine giriş süresi (dak.) & 837 & 7.75 \\
\hline Koridordan çıkarken koşma (Adet) & 809 & 7.49 \\
\hline Koridordan çıkarken atlama (Adet) & 328 & 3.04 \\
\hline Girişe kadar hayvana müdahale sayısı (Adet) & 238 & 2.20 \\
\hline Koridorda seslilik (Adet) & 219 & 2.03 \\
\hline Hayvanın geriye dönüşleri (Adet) & 183 & 1.69 \\
\hline
\end{tabular}

İncelenen özellikler bakımından hareketi reddetme, engelleme, kayma, düşme, vurma, sopa kullanımı, atlama, sıçrama gibi birçok olumsuz refah göstergeleri tespit edilmiştir. $\mathrm{Bu}$ anketteki, elektrikli alet kullanımı hayvan refah yönergelerinde kabul edilen değerlerin üzerinde gerçekleşmiştir (\% 5.5'e karş1 \% 11.55); seslilik sayıs1 (\% 1.4'e karş1 \% 2.03), tökezlemeler (\% 6.7 'ye karş1 $\% 11.58)$, düşmeler ( $\% 0.8$ 'e karş1 $\%$ 2) ve sıkıştırma kanalından atlayan ve kaçan sığırlar (\% 12.8'e karşı \% 10.33) olarak tespit edilmiştir. Goonewardane ve ark. (1999), elektrikli uyarıcılar kullanarak sıkıştırma yerine alınan hayvanların daha sonraki günlerde sıkıştırma yerine girmekte daha fazla problem çıkardıklarını bildirmektedir. Hayvanın çalışanlar ve uygulamadan kaçınma davranışı \% 16.38 olarak gerçekleşmiştir. Hayvanların çalışanlara yaklaşımı çalışanların hayvanlara yaklaşımı konusunda bilgi vermektedir. Littlefield ve ark. (2001), sıkıştırma yerinde sakin davranılan düvelerle yaptıkları çalışmada, hayvanları huylarına göre puanladıklarını ve huysuz olan düvelerin bölmeye en son girdiklerini bildirmektedirler. Ancak hayvanlara sakin ve yumuşak davranmanın problemleri önemli ölçüde azalttığını bildirmektedirler. Evcil hayvanların çevresinde bulunan ve çok büyük değişkenliğe sahip en önemli faktör insandır (Dantzer ve Mormede, 1983; Vieyra ve ark., 2000; Bozkurt ve ark., 2013). Hayvanla çalışma sırasındaki davranışlar hayvanın tepkisini doğrudan etkilemektedir. Hayvana yaklaşırken yapılan zorlama, bağırma, vurma gibi yanlış ve zorlayıcı uygulamalar hayvan refahını olumsuz yönde etkileyerek iş idaresi ve çalışan güvenliğinden başlayarak hayvan kayılarına kadar gidebilir. Tosunların hayvan bakım yerine giriş süresi ortalama 7.75 dakika olarak gerçekleşmiştir. Hayvanın hayvan bakım yerine giderken koridorlarda geriye dönüş oranı ise 1.69 olarak tespit edilmiştir. Geriye dönüş oranlarının yüksek olması hayvan koridorlarının genişliği ve daralma açıları ile ilgilidir. Geniş koridorlar içinde hayvanlar grup halinde olduklarında daha iyi hareket etmelerine rağmen geriye doğru hareket etme ihtimalleri artar. Bu amaçla hayvanların tartılması ve 


\section{Besi Hayvanlarında Yaralanmalar ve Önleme Yolları}

değerlendirmelerde bulunmak için uygun geçit yolları ve koridorlar ve hayvan sıkıştırma yerlerinin uygun özelliklere sahip olmas1 gerekir. Kıvrilan koridorların kullanımı ve koridorların kenarların hayvanın görüş açısını daraltarak stresi önleyecek şekilde etrafi göstermeyecek şekilde kapalı olması gibi uygulamalar önem taşımaktadır. Hayvanın ilerlemesi istenilen yöne doğru eğimli yapılması da sığırın ileri doğru hareketini kolaylaştıracak bir uygulamadır. Ayrıca sı ğıların toplanma yerine alınmasında birdenbire dar koridor kullanımı değil koridorun girişine doğru 30 derecelik açıyla daralarak girişe bağlanan giriş yeri öncesi daraltılmış toplanma yeri tasarımı da bu konuda avantajlıdır. Bu gibi düzenlemeler toplanma yerinde gruplaşma ve kümeleșmelerin önüne geçecektir. Hayvan koridorlarında hayvanın geriye hareketini engellemek ve istenen yöne gitmesini sağlamak uygun alet ekipman ile çok daha kolay ve etkili sonuçlar alınmaktadır (Gonyou, 2003).

Woiwode ve Grandin (2014), Amerika besi işletmelerinde hayvanlarla muamelede refah açısından değerlendirilmesi konulu çalışmada elde ettikleri değerlerin hayvan refah yönergelerinde kabul edilen değerlerin üzerinde olduğunu bildirmektedir. $\mathrm{Bu}$ çalışmada elde edilen değerler Woiwode ve Grandin (2014)'ın değerlerinden de yüksek düzeyde gerçekleşmiştir.

Çalışma sırasında hayvanlarda meydana gelen fiziksel yara bere, kırık çıkı vakaları ile mücadele davranış göstergeleri ise Çizelge 4'te verilmiștir.

Çizelge 4. Çalışma sırasında yapılan gözlem sonuçları

\begin{tabular}{|l|l|l|l|}
\hline Kriter & & Say1 & $\%$ \\
\hline Hayvanlarda fiziksel durum & Yara-Bere (Adet) & 468 & 4.33 \\
\cline { 2 - 4 } & Kırık, Çı1ık (Adet) & 120 & 1.11 \\
\hline \multirow{5}{*}{ Mücadele } & Kaçma (Adet) & 1021 & 9.45 \\
\cline { 2 - 4 } & Seslilik (Adet) & 219 & 2.03 \\
\cline { 2 - 4 } & Tekmeleme (Adet) & 757 & 7.01 \\
\cline { 2 - 4 } & Vurma (Adet) & 420 & 3.89 \\
\cline { 2 - 4 } & Çarpma (Adet) & 914 & 8.46 \\
\cline { 2 - 4 } & Kayma (Adet) & 941 & 8.71 \\
\hline
\end{tabular}

Gözlem çalışmaları sırasında hayvanlarda fiziksel durum değerlendirmesinde kırık çıkık oranının \% 1.11 yara-berelerin ise \% 4.33 düzeyinde olduğu anlaşılmaktadır. Tosunların bakım muamele anında stres göstergesi olan kaçma, seslilik, tekmeleme, vurma, çarpma ve kayma gibi koşullara karşı stresli tepkilerin yoğun olarak gözlendiği anlaşılmaktadır.

\section{Sonuc}

Sığır besiciliğinde üretimin farklı aşamalarında meydana gelen yara bere ve zedelenmeler son ürün olan ette de kalite kaybına ve verim düşüklüğü ile ekonomik kayıplara neden olmaktadır. Çalışma sırasında hayvanların fiziksel değerlendirmesinde kırık çıkık oranının $\% 1.11$, yara-berelerin ise $\% 4.33$ düzeyinde
Besi işletmelerinde sığırlarla yapılan işlemler sırasında çalışan ve hayvan açısından birçok stres koşulları oluşmaktadır. Bazı işletmelerde (\%4) hayvanla muamele için daha konforlu işlem yeri için alet özel mekân tasarımı yapılmış ise de çalışanların bu alanların kullanımı konusunda herhangi bir bilgisi eğitimi ve alt yapısı olmaması stresi daha da artırmaktadır.

olduğu anlaşılmıştır. Tosunların bakım muamele anında stres göstergesi olan kaçma, seslilik, tekmeleme, vurma, çarpma ve kayma gibi koşullara karşı stresli tepkilerin yoğun olarak gözlendiği anlaşılmaktadır. İşletmelerde sopa ve elektrikli şok cihazlarının hayvan yönlendirmede yüksek oranda kullanılıyor olması da dikkat çekici bir diğer sonuçtur. Besi 


\section{Besi Hayvanlarında Yaralanmalar ve Önleme Yolları}

işletmelerinde sığırlarla yapılan işlemler sırasında hem çalışan hem de hayvan açısından çok stresli koşullar oluşmaktadır. Bazı işletmelerde hayvan refahına uygun olması için özel alet ve mekân tasarımı yapılmış ise de çalışanların bu alanların kullanımı konusunda bilgisinin olmamas1 istenen sonucu vermenin önündeki en büyük engeldir. Ayrıca alet ve ekipman tasarımında yapilan temel hataların başında hayvanların geri dönmesini engelleyecek kapı veya panellerin (Grandin, 1994) düşünülmemiş olması da diğer bir önemli konu başlığıdır. İşletmelerde çalışanların hayvana yaklaşım ve yönetim becerileri konusunda eğitim alması ile bu oranların hayvan refah kriterlerine uygun şekle dönüştürülebileceği düşünülmektedir.

\section{Kaynaklar}

Bozkurt, Z., Kılıç, İ., Hacan Gücüyener, Ö., Lenger, Ö.F. (2013) İnsan-hayvan etkileşimlerinin hayvan refahına etkisi. Kocatepe Vet J 6(1): 41-50.

Brown, C. J., Gacula, M. (1964) Estimates of Heritability of Beef Cattle Performance Traits by Regression of Offspring on Sire 1, 2. Journal of Animal Science 23(2),

321-324. https://doi.org/10.2527/jas1964.232321 $\mathrm{x}$

Dantzer, R.D., Mormede, P. (1983) Stress in farm animals: a need for revaluation. $J$. Of Anim. Sci 57:6-18.

Eren, E. (2006) Kahramanmaraş İli Göksün ilçesinde sığır besiciliği yapan işletmelerin yapısı ve sorunları. Yüksek lisans tezi. Sütçü İmam Üniv. Fen Bilimleri Enst, Kahramanmaraş.

Koyubenbe, N. (2005) İzmir ili ödemiș ilçesinde süt sı ğırcılığının geliştirilmesi olanakları üzerine bir araştırma. Hayvansal Üretim Derg 46 (1): 8-13.

Gonyou, H.W. (2003) How animal handling influences animal behaviour. http://www.aginfonet.com/aglibrary/co ntent/prairie_swine_centre/95animal_b ehaviour.html

Goonewardane , L.A., Price, M.A., Okine, E., Berg, R.T. (1999) Behavioural responses to handling and restraint in dehorned and pooled cattle. Appl. Anim. Behav.Sci 64:159-167.

Göncü, S., (2019) Sığır Yetiştiriciliğinde Stressiz ve Güvenli Sığır Yönlendirme. Cilt 34, Say1 2, Sayfalar 161-170.

Göncü, S. (1993) Türkiye Kültür Irki Ve Kültür Irki X Yerli Irk Melezlerinde Besi Performansi Üzerinde Yapilan Araştırmalar.

http://www.muratgorgulu.com.tr/ckfind er/userfiles/files/TURKIYE\%20KULT UR\%20VE\%20MELEZ\%20SIGIRLA RDA\%20BESI\%20PERFORMANSI.p df

Grandin, T. (1994) Solving livestock handling problems. Veterinary medicine (pages, 989-998).

Grandin, T. (1997) Assessment of Stress during Handling and Transport. Journal of Animal Science 75(1):249-57.

Köknaroğlu, H., Demircan, V., Yılmaz, H., Dernek, Z. (2007) Besi sığırcıllı̆̆ üretim faaliyetinde üreticilerin eğitim düzeylerinin besi performans1 ve karlılığa etkisi. 5. Ulusal Zootekni Kongresi. 5-8 Eylül. Van, 92.

Littlefield, G., Grandin, T., Lanier, J.L. (2001) Quiet handling of heifers reduces aversion to restraint in a squeeze chute. http://ansci.colostate.edu/ ran/behavior/g1011.html.

Soyak, A., Soysal, M. İ., Gürcan, E.K. (2007) Tekirdağ ili süt sığırcıllğ 1 işletmelerinin yapısal özellikleri ve bu işletmelerdeki siyah alaca süt sığırlarının çeşitli morfolojik özellikleri üzerine bir araştırma. Tekirda ̆̆ Üniv. Ziraat Fak. Derg 4(3): 297-305.

Stermer, R. A., Camp, T.H. (1981) Feeder Cattle Stress During Handling and Transportation. Amer. Soc. Agric. Eng Paper No. 81-60001.

Şahin, K., Gül, A., Koç, B., Dağıstanlı, E. (2001) Adana ilinde entansif süt sığırcilığ1 üretim ekonomisi. Yüzüncü Yll Üniv. Ziraat Fak. Tarım Bilimleri Derg 11(2): 19-28.

Tugay, A., Bakır, G. (2004) Giresun Yöresindeki Sı ğırcılık İşletmelerinde Kullanılan Yem Çeşitleri ve Hayvan Besleme 
Alışkanlıkları. 4. Ulusal Zootekni Bilim Kongresi. 01-03 Eylül 2004. Isparta. 536-544.

TUIK, (2019) Hayvancilik istatistikleri. https://biruni.tuik.gov.tr/medas/?kn=10 $1 \&$ locale $=$ tr

Vieyra, J., Losada, H., Soriana, R., Cortes, J., Arias, L. (2000) Smallholder dairy cattle production in Xochimilco in the southeast of Mexico city: Effect of herdsman spatial behaviour of cattle during restricted grazing. Livestock Research for Rural Developmant, 12 (2).

Woiwode, R., Grandin, T. (2014) Survey of BQA Cattle Handling Practices That Occurred During Processing Feedlot Cattle Conference: 2014 ADSA-ASASCSAS Joint Annual Meeting.

Yıldırım, İ. (2000) Van İli Merkez İlçede Sığır Besiciliği İşletmelerinin Ekonomik Analizi. Yüzüncü Y1l Üniversitesi Ziraat Fakültesi Yayınları No. 20. Araştırma Serisi No. 1. Van, 52s. 
Besi Hayvanlarında Yaralanmalar ve Önleme Yolları 